\title{
Decreasing incidence of inflammatory bowel disease in Eastern Canada: a population database study
}

\author{
Desmond Leddin ${ }^{*}$, Hala Tamim ${ }^{2,3}$ and Adrian R Levy ${ }^{2}$
}

\begin{abstract}
Background: Nova Scotia has one of the highest incidences of inflammatory bowel disease (IBD) in the world. We wished to determine trends of IBD over time.

Methods: All Provincial residents have government provided health insurance and all interactions with the hospital, and physician billing systems, are captured on an administrative database. We used a validated measure to define incident cases of Crohn's (CD), ulcerative colitis (UC) and undifferentiated IBD (IBDU). Incidence rates of these diseases for the years 1996-2009 were calculated.

Results: Over the study period, 7,153 new cases of IBD were observed of which 3,046 cases were categorized as CD (42.6\%), 2,960 as UC (41.4\%) and 1,147 as IBDU (16.0\%). Annual age standardized incidence rates were very high but have declined for CD from 27.4 to 17.7/100,000 population and for UC from 21.4 to 16.7/100,000. The decline was seen in all age groups and both genders. The decrease was not explained by a small increase in IBDU.

Conclusion: The incidence of CD and UC are decreasing in Nova Scotia. If replicated elsewhere this indicates a reversal after a long period of increasing occurrence of IBD. This has implications for both epidemiology and health planning.
\end{abstract}

Keywords: Crohn's, Inflammatory bowel disease, Ulcerative colitis, Epidemiology

\section{Background}

Inflammatory bowel disease (IBD) is a gastrointestinal disorder which consists of Crohn's Disease (CD), Ulcerative Colitis (UC) and Undifferentiated IBD (IBDU). IBDU is diagnosed when the illness has features of both $\mathrm{CD}$ and UC [1].

The aetiology of these conditions remains unclear [2-6]. Incidence and prevalence rates are rising in many regions of the world including developing nations [2]. Escalating rates have led to an increased awareness of IBD given the significant burden of morbidity and high economic costs associated with it.

The prevalence and incidence of IBD has been studied extensively in recent years. The disease affects both genders and all ages. Molodecky et al. [3] conducted a

\footnotetext{
*Correspondence: dleddin@Dal.Ca

1 Department of Medicine, Dalhousie University, 912 Victoria, Victoria General Hsopital, Halifax, NS B3H 2Y9, Canada

Full list of author information is available at the end of the article
}

comprehensive systematic review of the literature which compared $\mathrm{CD}$ and $\mathrm{UC}$ rates across regions and over time. The incidence and prevalence were highest in western nations, specifically Northern Europe and Canada.

In Canada studies have been conducted to describe patterns of IBD occurrence within this country. Bernstein et al. [7] analyzed data from five provinces and extrapolated to produce nationwide incidence and prevalence estimates for both CD and UC. Consistent with other studies, there were considerable differences in rates across regions. The age adjusted incidence of Crohn's disease in Canada varied from 8.8/100,000 population in British Columbia to 20.2/100,000 in Nova Scotia.

The incidence of IBD varies with time [8,9]. Such changes may help identify factors contributing to the pathogenesis of the disease. Therefore it is important to measure a baseline and track changes over time using reliable and consistent data sources. The objective of this study was to determine the incidence of CD, UC and IBDU in Nova 
Scotia annually from 1996-2009 and assess changes in incidence over time.

\section{Methods}

Nova Scotia is located on the east coast of Canada and has advantages as a location for the study of incidence trends in IBD. The population is ethnically homogenous, and there is little in- or out-migration [10]. The province has a population of just over 920,000 which is of sufficient size to yield enough cases to make meaningful inferences about changes in incidence, the population is equally divided between rural and urban areas, has a high background incidence and prevalence of the diseases [7], and it has universal health care in which all residents of the province receive necessary health care regardless of their ability to pay. All residents have a health card, which is used when accessing care. All encounters with the health system are captured on a government database, and it has a population health research unit, which has access to all health encounter data. This is not a registry study but is based on health utilization data which captures every resident of the Province.

\section{Data collection}

The data for this study were based on the Nova Scotia administrative health care databases. All residents of the Province have publicly funded health insurance for physician and hospital care. Billings generated by patient interactions with hospital or physician services are submitted to the government for payment using unique patient identifiers. The Provincial Insurance payments database was used to determine Nova Scotia Medical Service Insurance eligibility, and for patient demographics. The Canadian Institute for Health Information Discharge Abstract database and Physician Billings claims database were used to obtain diagnosis and procedure codes for IBD. Records for the calendar years 1991 to 2010 inclusive were used.

The definition of IBD was based on a modification of the validated administrative case definition from Alberta [11] with a reported sensitivity and specificity of $77.9 \%$ and $99.8 \%$ respectively. Based on this case definition, Physician Claims and hospital Discharge Abstracts databases were searched for a diagnosis of IBD (i.e. ICD-9 codes of 555.x or 556.x; and ICD-10 codes of K50.x or K51.x).

Case definitions for CD (sensitivity of $91.1 \%$ and specificity of $98.7 \%$ ) and UC (sensitivity of $81.7 \%$ and specificity of $97.4 \%$ ) were also based on the validation study by Rezaie et al. [11] Within each administrative database (i.e. Discharge Abstract and Physician Billings claims databases) patients were given a +1 score for each ICD diagnostic code for UC (ICD-9 code 556.x, ICD-10 code K51.x) or a score of -1 for each ICD code for CD (ICD-10 code 555.x, ICD-10 code K50.x).
The diagnostic criteria are shown in Table 1. A patient with one hospitalisation or four physician claims would meet the criteria for a diagnosis of IBD. Following the diagnosis of IBD patients were sub classified by IBD type. If, for example, the patient had one hospitalisation with a discharge diagnosis of UC and one physician claims with a diagnosis of UC their cumulative score would be $(+2$ for the hospital discharge $)+(+1$ for the physician billing) $=+3$.

Since some subjects may not have been seen every year, incidence rates were calculated after excluding any subject with a physician billing or hospital discharge records with a diagnosis of the target diagnoses between 1991 and 1995. Hence, incidence rates were reported for the year 1996-2009. Date of first medical contact was considered the "diagnosis date" for estimating incidence rates.

\section{Statistical analysis}

The total number of incident cases of CD, UC and IBDU were calculated for women and men and by age group. To adjust for age distribution and compare across years, directly age-standardized incidence rates of $\mathrm{CD}, \mathrm{UC}$ and IBDU were calculated for women and men and overall. The 2006 Canadian population was used as the standard population. All rates were reported per 100,000 persons. Poisson regression was used to measure the effect of calendar year on the incidence of CD, UC, IBDU and IBD for each sex by age groups and overall. Year was included in the model as a categorical variable with the year 1996 being the reference category. Analysis was conducted using SAS 9.1 software [12].

\section{Ethics approval}

This study was approved by the Dalhousie University ethics committee and by the Capital District Health Authority ethics committee and is in compliance with the Helsinki

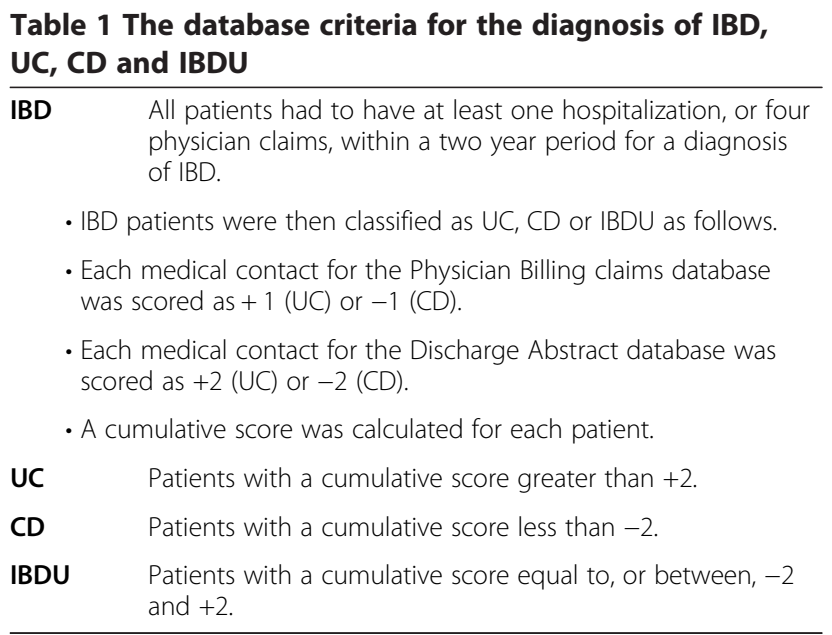


Declaration. Access to the health databases is controlled by Health Data Nova Scotia, and was approved by the access committee following review of the application and receipt of ethics approval.

\section{Results and discussion}

Over the 14 year period under study, across all age groups and both genders, a total of 7,153 incident cases of IBD were identified with 3,046 cases categorized as CD (42.6\%), 2,960 cases categorized as UC (41.4\%) and 1,147 cases categorized as IBDU (16.0\%).

With regard to the 3,046 incident cases of $\mathrm{CD}, 1,743$ (57.2\%) were in women and $1,303(42.8 \%)$ were in men whereas of the 2,960 incident cases of UC, 1,507 (50.9\%) were in women and 1,453 (49.1\%) in men. Of the 1,147 incident cases of IBDU, 617 (53.8\%) were in women and $530(46.2 \%)$ in men. Over $50 \%$ of the incident cases of IBD in men and women occurred among ages 20-59 years (Table 2).

Table 2 Total number (\%) of incident cases of CD, UC and IBDU in Nova Scotia, 1996-2009

\begin{tabular}{|c|c|c|c|c|c|c|}
\hline \multirow[b]{2}{*}{ Age group (years) } & \multicolumn{2}{|c|}{$C D$} & \multicolumn{2}{|c|}{ UC } & \multicolumn{2}{|c|}{ IBDU } \\
\hline & $N$ & $\%$ & $\mathrm{~N}$ & $\%$ & $\mathrm{~N}$ & $\%$ \\
\hline \multicolumn{7}{|l|}{ Women } \\
\hline$<10$ & 23 & 1.3 & 12 & 0.8 & 4 & 0.6 \\
\hline $10-19$ & 193 & 11.1 & 102 & 6.8 & 20 & 3.2 \\
\hline $20-29$ & 397 & 22.8 & 212 & 14.1 & 76 & 12.3 \\
\hline $30-39$ & 364 & 20.9 & 316 & 21.0 & 103 & 16.7 \\
\hline $40-49$ & 267 & 15.3 & 309 & 20.5 & 97 & 15.7 \\
\hline $50-59$ & 237 & 13.6 & 244 & 16.2 & 101 & 16.4 \\
\hline $60-69$ & 148 & 8.5 & 168 & 11.1 & 80 & 13.0 \\
\hline $70-79$ & 83 & 4.8 & 94 & 6.2 & 82 & 13.3 \\
\hline$\geq 80$ & 31 & 1.8 & 50 & 3.3 & 54 & 8.8 \\
\hline All women & 1743 & 100.0 & 1507 & 100.0 & 617 & 100.0 \\
\hline \multicolumn{7}{|l|}{ Men } \\
\hline$<10$ & 25 & 1.9 & 14 & 1.0 & 2 & 0.4 \\
\hline $10-19$ & 221 & 17.0 & 97 & 6.7 & 27 & 5.1 \\
\hline $20-29$ & 285 & 21.9 & 183 & 12.6 & 74 & 14.0 \\
\hline $30-39$ & 251 & 19.3 & 252 & 17.3 & 85 & 16.0 \\
\hline $40-49$ & 218 & 16.7 & 301 & 20.7 & 78 & 14.7 \\
\hline $50-59$ & 156 & 12.0 & 265 & 18.2 & 106 & 20.0 \\
\hline \multirow[t]{2}{*}{$60-69$} & 92 & 7.1 & 194 & 13.4 & 77 & 14.5 \\
\hline & \multicolumn{2}{|c|}{$C D$} & \multicolumn{2}{|c|}{ UC } & \multicolumn{2}{|c|}{ IBDU } \\
\hline Age group (years) & $\mathbf{N}$ & $\%$ & $N$ & $\%$ & $\mathrm{~N}$ & $\%$ \\
\hline $70-79$ & 43 & 3.3 & 112 & 7.7 & 57 & 10.8 \\
\hline$\geq 80$ & 12 & 0.9 & 35 & 2.4 & 24 & 4.5 \\
\hline All men & 1303 & 100.0 & 1453 & 100.0 & 530 & 100.0 \\
\hline
\end{tabular}

Abbreviations: $C D$ Crohn's disease, IBDU Undifferentiated inflammatory bowel disease, UC Ulcerative colitis.
The directly age-standardized rates of $\mathrm{CD}, \mathrm{UC}$ and IBDU allowed for comparisons across years with adjustment for age distribution over time. Decreases in incidence were observed both for women (CD from 31.5 to $19.1 / 100,000$ and UC from 20.3 to $16.9 / 100,000$ ) and men (CD 23.0 to 16.3 and UC from 22.6 to 16.6 per 100,000) over the study period. Age-standardized rates of IBDU increased both for women (from 8.4 to 12.1) and men (from 6.2 to 10.4) over study period (Table 3 and Figure 1).

The results in Table 3 are not based on the regression model. It is descriptive and we cannot make inference as to whether there is significant difference in incidence over time. The percent differences in incidence rate with time that is calculated from Table 4 are based on the Poisson regression where the outcome follows a Poisson distribution.

Results of the Poisson regression showed that there was a significant negative change in the overall ageadjusted rates relative to 1996 for CD and UC (Table 4). Among sexes combined, the decrease for $\mathrm{CD}$ was $32.5 \%$ (95\% CI, -39.8 to -24.2 ) and for UC $24.8 \%$ (95\% CI, -33.2 to -15.3$)$. In men, the decrease for $\mathrm{CD}$ was $32.9 \%$ (95\% CI, -43.8 to -19.9$)$ and for UC $29.0 \%$ (95\% CI, -40.3 to -15.6$)$. In women, the decrease for $\mathrm{CD}$ was $31.9 \%$ ( $95 \% \mathrm{CI},-41.6$ to -20.7$)$ and $20.0 \%(95 \% \mathrm{CI},-32.5$ to -5.3$)$ for UC.

Figure 2 shows incidence rates for CD, UC and IBDU over time for different age groups. For $\mathrm{CD}$, a decrease in

Table 3 Annual directly age-standardized incidence rates per 100,000 of CD, UC and IBDU by sex in Nova Scotia, 1996-2009

\begin{tabular}{|c|c|c|c|c|c|c|c|c|c|}
\hline & \multicolumn{3}{|c|}{ Women } & \multicolumn{3}{|c|}{ Men } & \multicolumn{3}{|c|}{ Sexes combined } \\
\hline & D & UC & IBDU & D & UC & IBDU & $C D$ & UC & IBDU \\
\hline \multicolumn{10}{|c|}{ Year } \\
\hline 1996 & 31.5 & 20.3 & 8.4 & 23.0 & 22.6 & 6.2 & 27.4 & 21.4 & 7.3 \\
\hline 1997 & 29.1 & 25.2 & 8.8 & 26.1 & 28.2 & 7.7 & 27.7 & 26.7 & 8.3 \\
\hline 1998 & 30.2 & 22.1 & 11.5 & 21.3 & 26.1 & 9.1 & 25.9 & 24.1 & 10.3 \\
\hline 1999 & 24.5 & 26.1 & 6.8 & 20.3 & 25.4 & 7.9 & 22.5 & 25.8 & 7.4 \\
\hline 000 & 28.2 & 23.9 & 8.1 & 17.6 & 27.8 & 8.0 & 23.1 & 25.8 & 8.1 \\
\hline 2001 & 22.2 & 21.5 & 9.4 & 23.4 & 22.0 & 6.2 & 22.8 & 21.8 & 7.9 \\
\hline 002 & 25.2 & 20.9 & 9.0 & 21.5 & 20.0 & 9.5 & 23.4 & 20.4 & 9.3 \\
\hline 2003 & 28.6 & 24.2 & 1 & 4 & 1 & 8.4 & 25.6 & 23.6 & 9.2 \\
\hline 2004 & 22.6 & 23.1 & 6.8 & 16.2 & 21.3 & 8.5 & 19.4 & 22.2 & 7.6 \\
\hline 05 & 27.0 & 22.2 & 8.8 & 20.7 & 17.2 & 8.6 & 24.0 & 19.8 & 8.7 \\
\hline 2006 & 23.2 & 21.3 & 7.5 & 15.7 & 21.8 & 8.1 & 19.5 & 21.6 & 7.8 \\
\hline 0 & 2 & 19.1 & 7 & 18.1 & 16.8 & 7.2 & 19.7 & 18.0 & 7.4 \\
\hline 2008 & 21.1 & 19.8 & 10.4 & 15.1 & 25.3 & 8.4 & 18.2 & 22.5 & 9.4 \\
\hline 009 & 19.1 & 16.9 & 12.1 & 16.3 & 16.6 & 10.4 & 17.7 & 16.7 & 11.3 \\
\hline
\end{tabular}

Abbreviations: $C D$ Crohn's disease, IBDU Undifferentiated inflammatory bowel disease, UC Ulcerative colitis. 


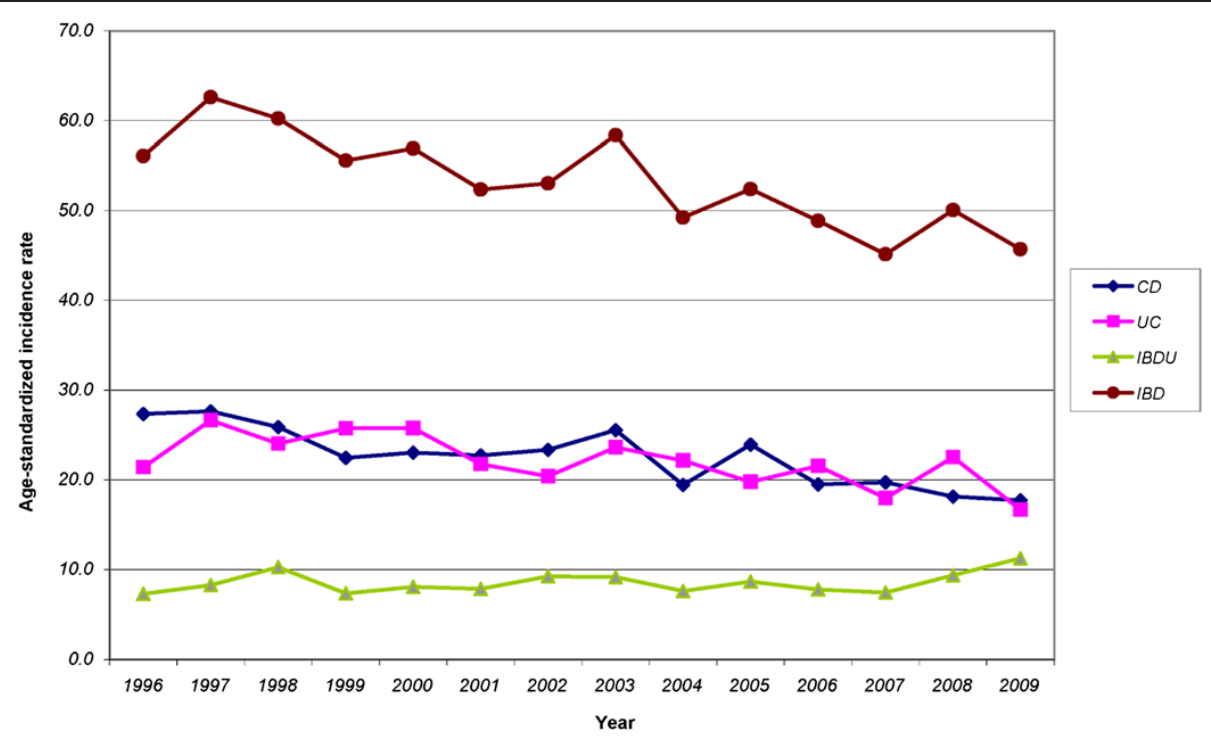

Figure 1 Age-standardized incidence rates of Crohn's Disease (CD), Ulcerative Colitis (UC), Undifferentiated Inflammatory Bowel Disease (IBDU) and Inflammatory Bowel Disease (IBD) in Nova Scotia, 1996-2009.

Table 4 Estimated age-sex specific percentage changes ( $95 \%$ confidence intervals) in rates of CD, UC, IBDU and IBD in Nova Scotia, 1996-2009

\begin{tabular}{|c|c|c|c|c|}
\hline & $\begin{array}{c}\text { CD } \\
\% \text { change }(95 \% \mathrm{Cl})\end{array}$ & $\begin{array}{c}\text { UC } \\
\% \text { change }(95 \% \mathrm{Cl})\end{array}$ & $\begin{array}{c}\text { IBDU } \\
\% \text { change }(95 \% \mathrm{Cl})\end{array}$ & $\begin{array}{c}\text { IBD } \\
\% \text { change }(95 \% \mathrm{Cl})\end{array}$ \\
\hline \multicolumn{5}{|l|}{ Women } \\
\hline$<20$ & $-25.7(-69.7,82)$ & $40.1(-59,378)$ & $48(-91.5,2487)$ & $-0.7(-50.5,99.3)$ \\
\hline $20-29$ & $-45.8(-77.9,33)$ & $-37.8(-81.7,111.5)$ & $20.9(-84.1,819.2)$ & $-38.1(-68.7,22.3)$ \\
\hline $30-39$ & $-29.6(-71.7,75.3)$ & $-35.3(-75.8,72.9)$ & $-18.9(-85.3,347.7)$ & $-30.7(-62.8,29.2)$ \\
\hline $40-49$ & $-16.9(-68.3,117.8)$ & $-11.3(-63.8,117.1)$ & $23.7(-75.1,515.1)$ & $-9.3(-50.6,66.3)$ \\
\hline $50+$ & $-28.5(-55.9,16)$ & $-14.2(-45.8,35.7)$ & $8.7(-40.9,100)$ & $-15.2(-36.7,13.5)$ \\
\hline All women (adjusted for age) & $-31.9(-41.6,-20.7)$ & $-20(-32.5,-5.3)$ & $11.5(-15.2,46.6)$ & $-21.4(-29,-13)$ \\
\hline \multicolumn{5}{|l|}{ Men } \\
\hline$<20$ & $-19.9(-64.1,78.6)$ & $111.7(-36.4,603.9)$ & $126.6(-82,2753)$ & $17.1(-38.1,121.5)$ \\
\hline $20-29$ & $-46.9(-81.2,50.6)$ & $-43.4(-84.5,107.2)$ & $78.4(-76.8,1269.4)$ & $-35.8(-69.7,35.9)$ \\
\hline \multirow[t]{3}{*}{$30-39$} & $-27(-75.6,118.2)$ & $-15.5(-71.6,151.3)$ & $31.3(-79.8,751.4)$ & $-15.4(-58.5,72.7)$ \\
\hline & $C D$ & UC & IBDU & IBD \\
\hline & $\%$ change $(95 \% \mathrm{Cl})$ & $\%$ change $(95 \% \mathrm{Cl})$ & $\%$ change $(95 \% \mathrm{Cl})$ & $\%$ change $(95 \% \mathrm{Cl})$ \\
\hline $40-49$ & $-37(-78.2,81.9)$ & $-46.8(-78.5,31.8)$ & $68.6(-71.9,910.5)$ & $-34.2(-65.3,24.9)$ \\
\hline $50+$ & $-20.1(-58.2,52.9)$ & $-32.7(-57.4,6.5)$ & $-11.3(-55.8,77.8)$ & $-25.1(-46.2,4.1)$ \\
\hline All men (adjusted for age) & $-32.9(-43.8,-19.9)$ & $-29(-40.3,-15.6)$ & $21.2(-9.5,62.4)$ & $-24.3(-32.2,-15.5)$ \\
\hline \multicolumn{5}{|l|}{ Sexes combined } \\
\hline$<20$ & $-22.6(-57.5,40.8)$ & $71.4(-27.3,304)$ & $108.3(-69.2,1307)$ & $8.2(-32.4,73.3)$ \\
\hline $20-29$ & $-46.4(-72.8,5.8)$ & $-40.5(-75.5,44.9)$ & $46.3(-65.2,515.2)$ & $-37.2(-62,4)$ \\
\hline $30-39$ & $-28.8(-64.7,43.6)$ & $-27.2(-64.9,51)$ & $0.8(-71.4,254.9)$ & $-24.6(-52.8,20.5)$ \\
\hline $40-49$ & $-26.6(-64,49.7)$ & $-31(-63.5,30.2)$ & $42(-57,368.4)$ & $-22(-49.8,21.1)$ \\
\hline $50+$ & $-25.8(-49.7,9.6)$ & $-24.2(-45.1,4.8)$ & $-1(-37.4,56.7)$ & $-20(-35.7,-0.4)$ \\
\hline Sexes combined (adjusted for age) & $-32.5(-39.8,-24.2)$ & $-24.8(-33.2,-15.3)$ & $17(-4,42.6)$ & $-22.8(-28.4,-16.8)$ \\
\hline
\end{tabular}



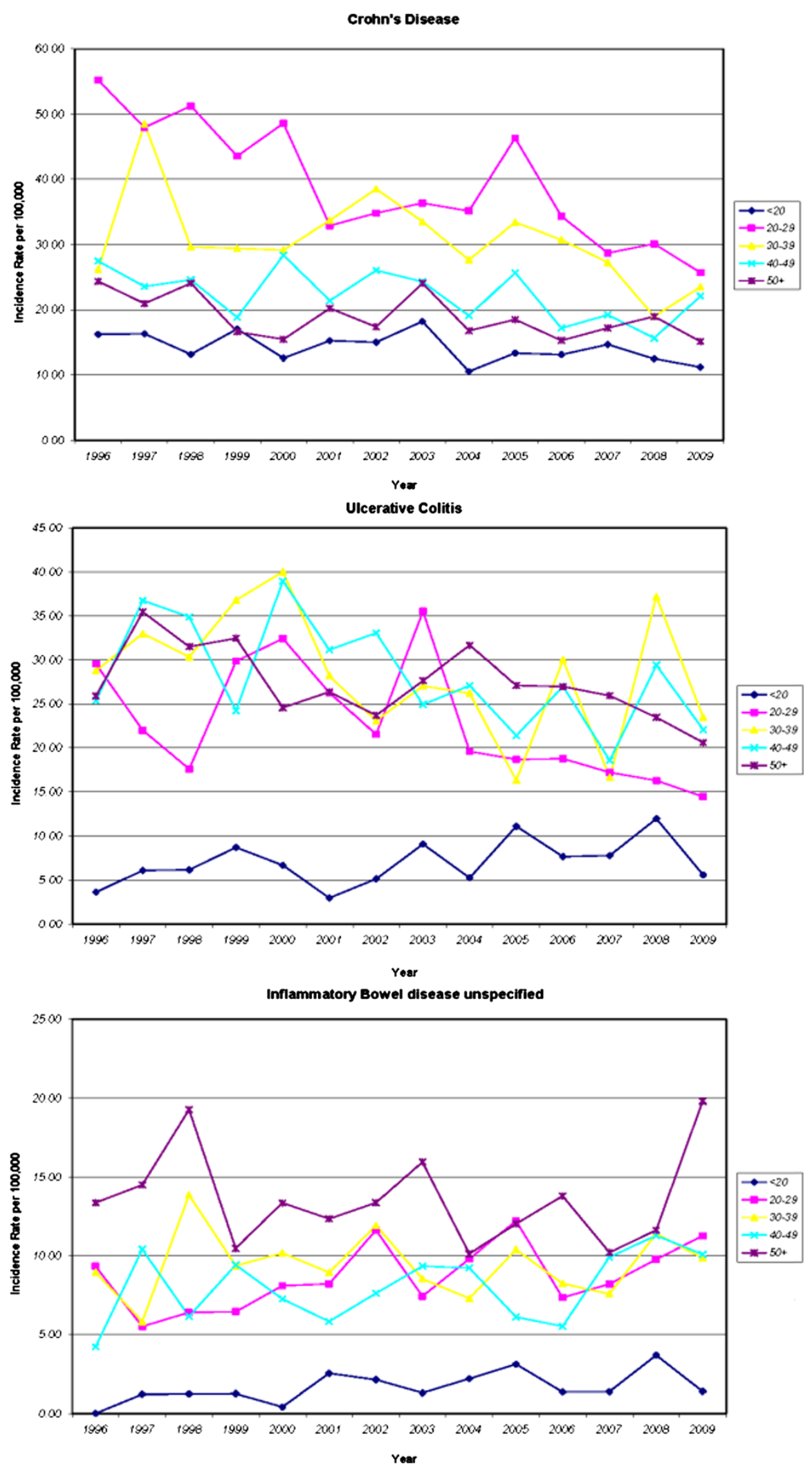

Figure 2 Annual incidence rates per 100,000 of Crohn's Disease (CD), Ulcerative Colitis (UC) and Undifferentiated Inflammatory Bowel Disease (IBDU) by Age, Nova Scotia, 1996-2009. 
incidence rates over time was observed for all age groups. For UC, a decrease in incidence rates was observed for all age groups except for age group less than 20 years of age where incidence rates increased over time period. On the other hand, incidence rates of IBDU showed no consistent change for different age groups over time.

Incidence rates of $\mathrm{CD}$ among youngest women in our cohort were almost double the rates of UC. This trend appears to level off for women 30 years of age and older where rates of $\mathrm{CD}$ and $\mathrm{UC}$ became equal. The same trend was not observed for men, where rates of $C D$ were higher than UC for those younger than 30 years of age. The equalization of the ratio of CD Disease to UC occurred at age of 30-39 years, at which point the ratio between $\mathrm{CD}$ and UC reversed (Figure 3).

Using a proxy for the incidence of both $\mathrm{CD}$ and UC we have shown evidence of a decrease in incidence of approximately $32 \%$ and $25 \%$, respectively, over a fourteenyear period from 1996-2009. The decline was observed in all age groups, for both diseases, and both genders with the exception of a non-significant increasing trend in ulcerative colitis under the age of 20 .

Results of the present study showed that agestandardized incidence rates of CD and UC for NS for the years 1998-2000 were higher than those reported by Bernstein et al. [7]. This is explained by differences in the case definitions used for each of the studies. In Bernstein et al. the IBD case definition required a patient to have at least five physician claims or hospitalizations for $\mathrm{CD}$ or UC if resident of the province for at least two years (or at least three claims if resident of the province for fewer than two years). In contrast, the definition of IBD used here, based on Rezaie et al. [11], relied on at least one hospitalization or four physician claims with an IBD diagnostic code within a 2-year period. Bernstein et al. [5] note that their definition leads to an underestimate of the incidence of IBD. Fransoo et al. [13] make clear that the Bernstein et al. case definition is better for estimating population prevalence than incidence of IBD. In addition the definition of Rezaie et al. [11] but not that of Bernstein et al. [5] captures cases best defined as IBDU. Our definition of IBD may underestimate milder cases who are not seen frequently, and therefore do not generate billing data, or who are not hospitalized.

The possibility of information bias is a concern. We mitigated this by using a validated measure of health care access to define incident cases [11]. We incorporated a wash out period of 5 years, to reduce the impact of including prevalent cases. Most importantly this is a comprehensive population based study. Improvements in treatment may have led to a decrease in interactions resulting in fewer patients meeting the definition. The major change in management has been the introduction of the biologics. Patients who are being treated with biologics are seen regularly in follow up. We also considered whether our data simply shows regression to the mean and consider this unlikely given the duration of the decline extending, as it does, over a period of fourteen years. The results could be secondary to reduced access to care, or a reduction in colonoscopy. Data from the Nova Scotia Department of Health (personal communication) shows that the number of colonoscopies in the Province increased by nearly $300 \%$ over the years of the study. This would favour an increase in IBD diagnosis, and IBD related billings, rather than the decrease observed.

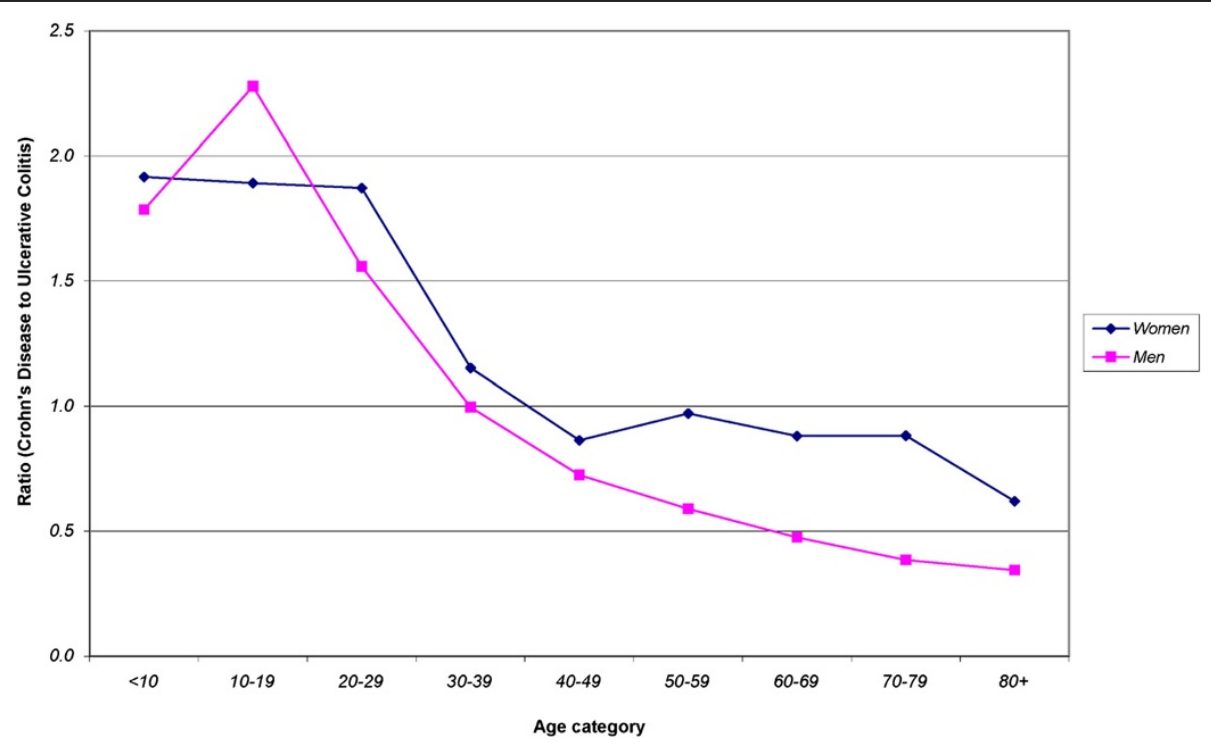

Figure 3 Ratio of incidence of Crohn's Disease (CD) to Ulcerative Colitis (UC) by Age in Nova Scotia, 1996-2009. 
There is no universally agreed national or international standard definition of IBD which can be utilised for IBD data base studies. A national study is required using a standardized case definition to verify our results.

The numbers of new cases of CD and UC were almost equal in our population but $\mathrm{CD}$ was more common in younger age groups. The incidence $\mathrm{CD}$ and $\mathrm{UC}$ equalize at age 50 years for women but for men over the age of 50 years UC was more common than CD. This is consistent with the prevalence of these diseases observed in a US population [14].

These results are in contrast to those reported in a recent systematic review (3), which concluded that no studies of $\mathrm{CD}$ disease, and only $6 \%$ of studies of $\mathrm{UC}$, have shown a significant decline in incidence. However, there are few population-based studies of incidence over time, and none of a population with a baseline incidence comparable to ours. Even fewer studies have reported incidence for the years beyond 2003. As can be seen from Table 3 a small decline in incidence was evident by 2003 but is more obvious from 2003-2009.

While no studies have reported a significant decline in CD several have shown either a small, non-significant decrease [15-18] or a plateau of incidence [19]. The report from Northern France, which described the incidence up to 2007, showed that the incidence of CD peaked in 1999 and is trending slightly downwards since [19].

The incidence for ulcerative colitis in the younger age groups showed a non significant trend upwards over the period under study. The incidence of IBD in the paediatric population has been reviewed [20]. Sixty percent of studies reported an increasing incidence of CD and 20\% of studies reported a rise in UC. The results reported here are consistent with those findings. It is possible that genetic factors play a greater role in younger onset IBD whereas environmental factors may be of greater importance in older age onset disease.

We observed a small and non significant increase in IBDU. Clinically IBDU is diagnosed when the disease has features of both ulcerative colitis and Crohn's disease [1]. Clinically IBDU may account for up to $12.6 \%$ of new cases of IBD in children and from $6 \%$ to $11.5 \%$ of cases in adults $[21,22]$, a proportion similar to that observed in our study. However we used a database scoring system to define cases of IBDU, not a clinical definition, and this may account for the relatively high percentage of IBDU cases in this study. It is possible that some of these cases are actually UC or CD but even if they were ascribed to either group the total number of new cases of IBD shows a decline.

There is little in- or out-migration to Nova Scotia therefore the genetic pool is stable [10] and the results may point to an environmental factor. One environmental change, with the potential to affect all residents, was the addition of folic acid to cereals starting in 1998. This was done to reduce the incidence of neural tube defects in newborns [23].

\section{Conclusions}

The evidence from this study indicates that incidence rates of both $\mathrm{CD}$ and $\mathrm{UC}$ are declining. Similar studies of secular trends in these conditions from other jurisdictions will be of interest to determine if the decline is a more universal observation. These results need to be replicated in countries with a high incidence and they may only to applicable to areas where the starting incidence is high. If replicated elsewhere this indicates a reversal after a long period of increasing occurrence of IBD. This has implications for both epidemiology and health planning.

\section{Abbreviations}

CD: Crohn's disease; IBDU: Undifferentiated inflammatory bowel disease: UC: Ulcerative colitis.

\section{Competing interests}

The authors declare that they have no competing interests.

\section{Authors' contributions}

$\mathrm{DL}$ developed the project and conceived the idea behind the study and was involved in interpretation and writing the manuscript. HT was involved in the design, execution of the study, analysis and writing. AL provided intellectual input, guidance and directly contributed to interpretation. All authors read and approved the final manuscript.

\section{Acknowledgements}

The project was supported in part by an unrestricted grant from Janssen Inc. The work was independent of funding received.

\section{Author details}

'Department of Medicine, Dalhousie University, 912 Victoria, Victoria General Hsopital, Halifax, NS B3H 2Y9, Canada. Epidemiology and Community Health, Dalhousie University, Halifax, Canada. ${ }^{3}$ Kinesiology and Health Sciences, York University, Toronto, Canada.

Received: 2 March 2014 Accepted: 5 August 2014

Published: 9 August 2014

\section{References}

1. Geboes K, Colombel JF, Greenstein A, Jewell DP, Sandborn WJ, Vatn MH, Warren B, Riddell RH: Indeterminate colitis: a review of the concept-what's in a name? Pathology Task Force of the International Organization of Inflammatory Bowel Diseases. Inflamm Bowel Dis 2008, 14(6):850-7.

2. Baumgart DC, Bernstein CN, Abbas Z, Colombel JF, Day AS, D'Haens G, Dotan I, Goh KL, Hibi T, Kozarek RA, Quigley EM, Reinisch W, Sands BE, Sollano JD, Steinhart AH, Steinwurz F, Vatn MH, Yamamoto-Furusho JK: IBD Around the world: comparing the epidemiology, diagnosis, and treatment: proceedings of the World Digestive Health Day 2010-Inflammatory Bowel Disease Task Force meeting. Inflamm Bowel Dis 2011, 17(2):639-44.

3. Molodecky NA, Soon IS, Rabi DM, Ghali WA, Ferris M, Chernoff G, Benchimol El, Panaccione R, Ghosh S, Barkema HW, Kaplan GG: Increasing incidence and prevalence of the inflammatory bowel diseases with time, based on systematic review. Gastroenterology 2012, 142(1):46-54.

4. Lowe A-M, Roy PO, B-Poulin M, Michel P, Bitton A, St-Onge L, Brassard P: Epidemiology of Crohn's disease in Québec. Canada Inflamm Bowel Dis 2009, 15(3):429-435.

5. Bernstein CN, Blanchard JF, Rawsthorne P, Wajda A: Epidemiology of Crohn's disease and ulcerative colitis in a central Canadian province: a population-based study. Am J Epidemiol 1999, 149(10):916-24.

6. Blanchard JF, Bernstein CN, Wajda A, Rawsthorne P: Small-area variations and sociodemographic correlates for the incidence of Crohn's disease and ulcerative colitis. Am J Epidemiol 2001, 154(4):328-35. 
7. Bernstein CN, Wajda A, Svenson LW, MacKenzie A, Koehoorn M, Jackson M, Fedorak R, Israel D, Blanchard JF: The epidemiology of inflammatory bowel disease in Canada: a population-based study. Am J Gastroenterol 2006, 101(7):1559-68.

8. Hanauer SB: Inflammatory bowel disease: epidemiology, pathogenesis, and therapeutic opportunities. Inflamm Bowel Dis 2006, 12:S3-9.

9. Loftus EV Jr: The burden of inflammatory bowel disease in the United States: a moving target? Clin Gastroenterol Hepatol 2007, 5(12):1383-84.

10. Government of Nova Scotia: Economics and Statistics. Archived daily statistics. www.gov.ns.ca (accessed 9 February 2011).

11. Rezaie A, Quan H, Fedorak RN, Panaccione R, Hilsden RJ: Development and validation of an administrative case definition for inflammatory bowel diseases. Can J Gastroenterol 2012, 26(10):711-17.

12. AS Institute Incorporation: SAS Institute Incorporation. NC, USA: SAS Institute Incorporation, Cary; 2002-2003.

13. Fransoo R, Martens P, The Need to Know Team, Burland E, Prior H, Burchill C, Chateau D, Walld R: Sex Differences in Health Status, Health Care Use, and Quality of Care: A Population-Based Analysis for Manitoba's Regional Health Authorities. Manitoba Centre for Health Policy: Winnipeg, MB; 2005.

14. Kappelman MD, Moore KR, Allen JK: Recent Trends in the Prevalence of Crohn's Disease and Ulcerative Colitis in a Commercially Insured US Population. Dig Dis Sci 2013, 58(2):519-25.

15. Ekbom A, Helmick C, Zack M, Adami HO: The epidemiology of inflammatory bowel disease: a large, population-based study in Sweden. Gastroenterology 1991, 100(2):350-8.

16. Green C, Elliott L, Beaudoin C, Bernstein CN: A population-based ecologic study of inflammatory bowel disease: searching for etiologic clues. Am J Epidemiol 2006, 164(7):615-23.

17. Sedlack RE, Nobrega FT, Kurland LT, Sauer WG: Inflammatory colon disease in Rochester, Minnesota, 1935-1964. Gastroenterology 1972, 62(5):935-41.

18. Romberg-Camps MJ, de Kruijs MA H-v, Schouten LJ, Dagnelie PC, Limonard CB, Kester AD, Bos LP, Goedhard J, Hameeteman WH, Wolters FL, Russel MG Stockbrügger RW: Inflammatory Bowel Disease in South Limburg (the Netherlands) 1991-2002: Incidence, diagnostic delay, and seasonal variations in onset of symptoms. J Crohns Colitis 2009, 3(2):115-24.

19. Chouraki V, Savoye G, Dauchet L, Vernier-Massouille G, Dupas JL, Merle V, Laberenne JE, Salomez JL, Lerebours E, Turck D, Cortot A, Gower-Rousseau C, Colombel JF: The changing pattern of Crohn's disease incidence in northern France: a continuing increase in the 10- to 19-year-old age bracket (1988-2007). Aliment Pharmacol Ther 2011, 33(10):1133-42.

20. Benchimol El, Fortinsky KJ, Gozdyra P, Van den Heuvel M, Van Limbergen J, Griffiths AM: Epidemiology of pediatric inflammatory bowel disease: a systematic review of international trends. Inflamm Bowel Dis 2011, 17(1):423-39.

21. Prenzel F, Uhlig HH: Frequency of indeterminate colitis in children and adults with IBD - a metaanalysis. J Crohns Colitis 2009, 3(4):277-81.

22. García Rodríguez LA, González-Pérez A, Johansson S, Wallander MA: Risk factors for inflammatory bowel disease in the general population. Aliment Pharmacol Ther 2005, 22(4):309-15.

23. De Wals P, Tairou F, Van Allen Ml, Uh SH, Lowry RB, Sibbald B, Evans JA, Van den Hof MC, Zimmer P, Crowley M, Fernandez B, Lee NS, Niyonsenga T: Reduction in neural-tube defects after folic acid fortification in Canada. N Engl J Med 2007, 357(2):135-42.

doi:10.1186/1471-230X-14-140

Cite this article as: Leddin et al:: Decreasing incidence of inflammatory bowel disease in Eastern Canada: a population database study. BMC Gastroenterology 2014 14:140.

\section{Submit your next manuscript to BioMed Central and take full advantage of:}

- Convenient online submission

- Thorough peer review

- No space constraints or color figure charges

- Immediate publication on acceptance

- Inclusion in PubMed, CAS, Scopus and Google Scholar

- Research which is freely available for redistribution

Submit your manuscript at www.biomedcentral.com/submit
Ciomed Central 